\title{
Let us talk: shaping linguistic well-being through differentiated tasks and conversation - report
}

\author{
ISSN 2657-9774; https://doi.org/10.36534/erlj.2021.02.04 \\ Luisito M. Nanquil \\ Bulacan State University \\ luisito.nanquil@bulsu.edu.ph
}

\begin{abstract}
In the new setting filled with anxiety and stress as encountered by many learners, it is but necessary that language teachers and other specialisms should recognize and respect the health, emotions, and wellbeing of learners by using conversation and differentiated tasks to help and assist them feel care, respect, and inclusion even on the flexible learning climate and environment. Language instruction faces a lot of challenges nowadays, especially, in the $21^{\text {st }}$ century education. It is not easy to hold the attention of our learners. The teacher has to experiment a lot of approaches and strategies to make the class attentive and receptive. But these efforts are futile if the teacher fails to meet basic needs of learners such as classroom conditions, instructional design, and linguistic wellbeing. Having a thought of these situations, this article aims to provide insights in the form of strategies and techniques that could be used by the language teachers to provide effective and engaging classroom environments in language teaching that will consider and shape linguistic wellbeing.
\end{abstract}

Key words: linguistic wellbeing, conversation, differentiated instruction, language teaching

\section{Linguistic wellbeing and social-emotional aspect}

If learners have stable social and emotional well-being, then their language and linguistic well-being can be stable and secured as well. But this is only possible if all efforts and strategies to apply will be observed by the language teacher.

In the new setting filled with anxiety and stress as encountered by many learners, it is but necessary that language teachers and other specialisms should recognize and respect the health, emotions, and well-being of learners by using conversation and differentiated tasks to help and assist them feel care, respect, and inclusion even on the flexible learning climate and environment.

Up to now, we are not yet sure when this pandemic reaches its end. We, however, should cope with the effects, impact, and realities that distract and disrupt the linguistic and social well-being of our students. Our learners are evidently struggling to

More often, there are teachers who do not notice or are unmindful of the conditions of their students. They should be sensitive and reasonable when it comes to the varying needs of learners affecting their linguistic wellness and communicative reactions and responses.

\section{Learning and learner situation during uncertain time}

For every word and utterance, we give there is a message. Even our students, when they speak, we can feel and analyze their emotions and feelings. On the new setting brought about by pandemic, it is hard to tell whether or not learners are physically and emotionally okay except if we provide clear dialogue with them. Perhaps the biggest query here is "How could we examine and feel the current wellbeing of our students when we are in the virtual environment"? This question fuels a lot of realities and challenges because each of our students has his own anxiety, stress, predicament, and other learning 
issues. Despite disruption of physical interaction, language and linguistics professors are trying their best to maximize learning opportunities to ensure that their students are developing their language skills. Will that be feasible and possible? How about when learners do not have access to internet?

Using conversations, the researcher accepts and acknowledges the opinions, styles, cultures, interests, and personalities of his online classes. In this way, students who are mostly experiencing internal issues can be motivated to participate and share their voices and feelings. Conversely, some do not want to speak up but they get the chance to listen. In some ways or the other, when students feel they are welcome, their linguistic well-being is respected and protected. They reach the stage of enlightenment, realization, and mindfulness where they realize the beauty of communication and expression with the kind support of the teacher.

The thoughts and reflections of our learners are rich however, if there is interruption of their language well-being and their social aspect definitely they will not share and express themselves. The primary goal of this paper is to analyze and describe the linguistic well-being of some learners in the Philippines and suggest strategies such as conversation and differentiated instruction to address the issues and concerns.

As students join the online classes, language teachers can provide a wide-array of activities and (pedagogical) tasks that can amuse, engage, and stimulate their minds. Furthermore, there are varied activities that can protect and consider the language well-being of the learners.

As language teachers present new lessons and as learners participate in the virtual classes, the teacher can give "sharing period" in which the learners are asked "How are you?". Later, the language teacher offers free and exclusive consultation periods so that he can identify the concerns or problems of the student. In this way, learners will feel they are respected, accepted, and protected.

Among the conversations, when we ask comforting questions such as "How are you?" "How is everybody?" we can elicit responses from members of the class. Their words and responses can help us determine if they are doing well and good. This is the extent when the responses of the students as a form of linguistic data can inform us that they are or not in good shape. Our role then is to spend a moment helping the learners cope with predicaments and problems by giving them pieces of advice which can uplift and motivate them to stand and face the situation. This is the very reason why it is imperative for us to listen to the words of learners because from that angle, we can examine the situation and we can look for possible intervention.

The use of differentiated tasks is appropriate in the online class, even with home schooled learners.

What varied and multifarious strategies can the language teacher apply to engage and build the social, emotional, and linguistic well-being of ESL students? There are many but we will only list and share the most applicable and appropriate ones. We say appropriate because there is no one-size fitting all. Based on the needs and issues, we can redesign the learning climate and address all the problems and needs of the students.

I basically begin the class checking the attendance using a tool. I am trying to reach to students by telling them how are they and many times we open with solemn prayer. I am trying to make them feel that there is always hope and light despite the health crisis that all of us are experiencing.

Graphic organizers can serve as motivator and tool for collection of ideas among learners. there are plenty of designs found on the web. Portfolio is both an assessment tool and a project that can showcase the skills and talents of students. On the actual virtual classes, learners can be grouped by the teacher using break out rooms where they can connect and share their ideas and feelings. Indeed, there are many tasks and activities that can be performed either online and offline but the language teacher should be flexible and reflective in providing clear and comprehensible directions. The teacher should guide and motivate learners to be engaged and feel well so that they can be linguistically prepared and will do their best to be active and dynamic. 
Often times, some language teachers do not see the stage fright and butterflies in tummy of many learners. if this scenario is hard to detect and identify in traditional classroom setting, how much more when learners are on virtual platform.

\section{Literature review}

Movitz and Holmes (2007) share their experiences in teaching high school where they incorporated learning stations while handling a medieval unit. One key point on their reflection is that learners don't outgrow their love of learning through hands-on and multisensory tasks. They witnessed increased student participation and more meaningful experiences through stations.

Cooperative learning, on the other hand, can be an effective mixture together and simply asking students to work together lacks the organization and same goals of effective cooperative learning. Cooperative learning is not just working in groups; rather, it is purposive, tactical, and structured instructional strategy that can promote healthy learning environment.

Fielder and Brent (2007) provide logical reasons as to why cooperative learning is attainable and effective. Students can learn better by performing something active, rather than simply sitting and listening. They also believe that cooperative learning benefits smarter students, who are put in the position of having to explain and summarize concepts to team members who contribute to success of the team.

Macmillan (2021) online course (cited by Spencer) offers insight that says building relationships that are meaningful and not just transactional. The teacher has to allocate time in each lesson to learn about the lives of his students. The teacher should find out what inspires students and what they feel passionate about. They can also talk about themselves and value communication practice. With the chance provided by the teacher to understand his students and understand one another, this situation forges stronger bonds among members of the class leading to creating a more supportive and inclusive classroom environment.

It also suggests teachers to be transparent by offering full disclosure on why the teacher presents the lesson and how tasks and materials are designed to help students achieve progress. Explaining the purpose of the tasks, activities, and approaches to students provide them a roadmap for completion and motivation.

\section{Experiences and reflections}

In our everyday interaction in school, we are able to observe events, changes, phenomena, and realities. If teachers are aware of what is happening around and inside the class, they could practically and wisely improve themselves. Opportunities are boundless. They are around us and they could also be within us. Through reflective teaching practices, language teachers can review and examine their experiences, interactions with others, lessons, devices, and thoughts. If we keep our thoughts and have them examined, we could definitely pick the best strategies, perspectives, and practices which we could apply in our future sessions in the class. The reflective teacher is someone who is willing to undergo changes as long as these changes and innovations could make him/her become better. Another advantage of reflections is being inclined with professional advancement. The reflective teacher has the desire to achieve excellence through exposure to seminars, graduate courses, forums, consultations, self-analysis, classroom observations, and research.

These suggestions are like tools for the improvement of instructional design in the class. In the globalized learning environment, everything in the classroom is managed and controlled by the reflective language teacher. Is it possible for the teacher to create an engaging learning environment? Yes, of course! It only takes a lot of willingness, patience, and critical thinking for the teacher to provide the best intellectual atmosphere for his/her students. Although, a conducive learning atmosphere may 
not be achieved in split of seconds, the language teacher can gradually upgrade and enhance the conditions of the classroom. It is also essential that the language teacher continuously reads books and studies that are aligned with his/her specialization so that his/her knowledge and insights will be honed and shaped.

It is recommended that in any curriculum, inclusion of social emotional learning and linguistic well-being are integrated or imbedded because we do not know how our students feel and think behind those cameras during online sessions. As language educators, we must check and consider the wellbeing of learners. We can detect and verify their emotions through conversations and reactions.

\section{Conclusion and implications}

This paper aims to share insights from the experiences and testimonials of language teachers who have been trying to become effective and productive in ESL online instruction despite the effects of pandemic. It tries to examine the causes of linguistic problems caused by the phenomenon and how it affects and influences the well-being of students.

The researcher narrates professional experiences during the time of health crisis in which learners and teachers meet and communicate through virtual platforms. Furthermore, he connects observations and experiences with related studies and literature for validation of facts and data.

Many students could hardly recite and participate. Their tone and voices denote struggle in learning the language due to anxiety and stress. They get worried how they can survive the financial crises since their parents are laid off due to bankruptcy and cease of company operations.

In the Philippine setting, there were reports and narrations on learners who do not want to participate in online classes for some unavoidable circumstances. Language teachers with the aid of stakeholders continue to analyze the situation and devise alternatives in order to accommodate and address the diverse needs of the learners.

Using varied strategies, teachers can offer students alternative routes through the learning jungle that will increase their chances of reaching their temples at the same time, allowing them pick up gold along the way.

In a positive learning environment, learners are engaged, safe, connected, and supported. Healthy and safety issues and efficient communication with both parents and teachers are also highly emphasized for a successful learning outcome. In this aspect, the role of collaboration plays a significant role. By incorporating collaborative and learner-centered strategies, teachers can make a difference in the lives of students hence, preparing them for the real world and the workplace.

\section{References}

Fielder, R.M., Brent, R. (2007). Cooperative learning, in: P.A. Mabrouk (Ed.), Active learning: Modules from the analytical sciences (pp. 34-53). Washington, D.C. American Chemical Society.

Movitz, A.P., Holmes, K.P. (2007). Finding center: How learning centers evolved in a secondary, studentcentered classroom. English Journal, 96(3): 68-73.

Spencer, D. Social and emotional learning (SEL) in the secondary classroom (2021). https://www.macmillanenglish.com/us/training-events/events-webinars/event/dave-spencer-socialand-emotional-learning-sel-in-the-secondary-classroom 